\title{
International System of Units
}

\author{
National Cancer Institute
}

\section{Source}

National Cancer Institute. International System of Units. NCI Thesaurus. Code C42541.

The International System of Units (Systeme International d'Unites, SI) is a decimal system of weights and measures derived from and extending the metric system of units established through the Treaty of the Meter (Convention du Metre) signed in Paris in 1875 and currently signed by 48 nations including all the major industrialized countries. The $\mathrm{SI}$ is maintained by the International Bureau of Weights and Measures (BIPM, for Bureau International des Poids et Mesures), and is updated every few years by an international conference, the General Conference on Weights and Measures (CGPM, for Conference Generale des Poids et Mesures). SI has a short list of base units defined in an absolute way without referring to any other units: the metre, the kilogram, the second, the ampere, the kelvin, the mole, and the candela. The base units are consistent with the part of the metric system called the MKS system. 